\title{
ENFERMAGEM EM ESTOMATERAPIA NO TELESSAÚDE UERJ: RELATO DE EXPERIÊNCIA
}

\author{
Nursing in Stomatherapy in Telehealth UERJ: Case Studies \\ Norma Valéria Dantas de Oliveira Souza'; Helena Maria Scherlowski Leal David²; \\ Vanessa Cristina Mauricio ${ }^{3}$; Carolina Cabral Pereira da Costa ${ }^{4}$
}

Resumo Trata-se de um relato de experiência sobre as participações das autoras em atividades desenvolvidas pelo Projeto Telessaúde UERJ. Esta atuação foi considerada profícua, pois contribui para a construção e a consolidação do conhecimento técnico e científico de profissionais da saúde, ajuda na qualificação do cuidado e possibilita o contato com estratégias de ensino-aprendizagem diferenciadas e inovadoras.

Palavras-chave: Estomaterapia, Enfermagem, Educação a distância, Tele-enfermagem, Telessaude.

Abstract This is an account of experience on the holdings of the authors in some activities developed by the Telehealth Project UERJ. This performance was considered useful as it has contributed to the construction and consolidation of technical and scientific knowledge of health care professionals, help in qualifying and care enables contact with differentiated teaching and learning strategies and innovative.

Keywords: Stomatherapy, Nursing, Distance education, Telenursing, Telehealth.

\footnotetext{
1.E-mail: norval_souza@yahoo.com.br.Professora Adjunta da ENF/UERJ. Coordenadora da Especialização em Estomaterapia da ENF/UERJ. Professora Permanente do Programa de Pós Graduação Strictu sensu da ENF/UERJ. Procientista da UERJ. - Enfermeira. Doutora em Enfermagem; 2. Professora Adjunta da ENF/UERJ. Professora Permanente do Programa de Pós Graduação Strictu sensu da ENF/UERJ. Procientista da UERJ. - Enfermeira. Doutora em Enfermagem; 3. Enfermeira do Ministério da Saúde (INTO/MS) e Hospital de Geral de Guarus. - Enfermeira. Mestre em Enfermagem. Doutoranda da ENF/UERJ. Especialista em Clínica Médica e Cirúrgica, em Terapia Intensiva e em Estomaterapia; 4. Professora Substituta da ENF/UERJ. - Enfermeira. Mestranda em Enfermagem da ENF/UERJ. Especialista em Enfermagem do Trabalho e em Estomaterapia. Recebido em 26/03/2014. Aceito, após revisão, em 27/05/2014.
} 


\section{Introdução}

As tecnologias de comunicação e informação virtuais surgem como ferramentas importantes e como alternativas para a educação em saúde da população. Nessa área, a educação a distância configura-se por meio do oferecimento de cursos de extensão, aperfeiçoamento, especialização e educação permanente'.

O Projeto Telessaúde Brasil caracteriza-se como um instrumento para desenvolver a educação a distância, viabilizando inúmeras atividades que auxiliam na qualificação de profissionais de saúde e estudantes. No Estado do Rio de Janeiro, o Projeto foi criado com o intuito de atender a demanda dos profissionais da Estratégia da Saúde da Família, contando com equipe multiprofissional qualificada e especializada, ofertando atividades nas áreas de pesquisa colaborativa, tele-educação e tele-assistência ${ }^{2,3,4}$.

Este texto objetiva descrever um relato da experiência relacionado à participação das autoras em atividades desenvolvidas pelo Telessaúde UERJ, oferecendo mais uma maneira de socializar essa estratégia de ensinoaprendizagem, caracterizada como dinâmica e aprazível para diversos profissionais.

\section{Relato da Experiência}

As autoras iniciaram suas participações no Projeto no ano de 2010, desenvolvendo atividades ligadas à área de Enfermagem em Estomaterapia. A primeira atuação no Telessaúde foi em palestras sobre cuidados com lesões de pele e estomas, por meio de transmissão simultânea, para usuários cadastrados e profissionais da Estratégia da Saúde da Família, em âmbito nacional. Constatou-se a participação efetiva de estudantes e profissionais de saúde, especialmente da Enfermagem, destacando-se a importância da atividade para o processo de ensinoaprendizagem e para a integração de profissionais das várias regiões do país.
Devido à expansão e relevância da temática, elaborouse um curso on-line, com dez horas de aula e disponibilizado aos usuários cadastrados, abordando a problemática biopsicossocial dos clientes estomizados.

A partir de março de 2013, as autoras ingressaram no grupo de teleconsultoria da área de Enfermagem em Estomaterapia. Essa outra atividade tem possibilitado, igualmente, a ampliação e consolidação de conhecimentos através do recebimento on-line de questionamentos acerca dos cuidados a serem realizados com clientes que apresentam estomias e feridas agudas e crônicas. Verifica-se que as solicitações por consultorias são oriundas de diversas localidades do Brasil e requeridas por profissionais de diferentes categorias profissionais. Assim, consideramos que a teleconsultoria também é uma estratégia que ajuda a qualificar o cuidado prestado na área da Estomaterapia e contribui para a capacitação de outros profissionais não incluídos na equipe de Enfermagem.

\section{Discussão}

A especialidade Estomaterapia surgiu no Brasil na década de 1990, na Universidade de São Paulo. $\mathrm{O}$ enfermeiro estomaterapeuta atua em três áreas: $\mathrm{O}$ cuidado aos clientes estomizados; a assistência a pessoas com feridas, agudas e crônicas; e a assistência aos indivíduos com incontinência, anal e/ou urinária 5 .

A busca por aprendizado nessa área relaciona-se com a elevação no número de atendimentos a clientes com lesões de pele, estomas e incontinências, além da existência de inúmeros equipamentos, coberturas e adjuvantes no tratamento desses problemas de saúde, os quais são lançados no mercado e consumidos de forma dinâmica e contínua. Desse modo, evidencia-se o incremento da curiosidade técnica e científica dos profissionais, impulsionando-os para a capacitação na área. 
As atividades em Estomaterapia fornecidas pelo Telessaúde oferecem aos estudantes e profissionais de saúde, subsídios para atualização na área e resolução de questionamentos, por enfermeiros especialistas. Logo, o atendimento à clientela pode ser melhorado com essa ferramenta pedagógica; por meio do suporte on-line, o conhecimento é disponibilizado para locais que não possuem cursos de especialização tradicionais e/ou com especialistas na área.

A especialidade, mesmo sendo exclusiva dos enfermeiros, conta com o auxílio dos demais profissionais de saúde, no atendimento à clientela. Justifica-se, assim, a participação de profissionais de diversas áreas nas palestras simultâneas e nas teleconsultorias, fortalecendo os princípios do Programa Telessaúde e propiciando bases para um atendimento holístico aos indivíduos.

\section{Comentários Finais}

As diversas modalidades de educação a distância alargam-se constantemente em nosso país, possibilitando acesso ao saber técnico e científico por indivíduos residentes em diferentes localidades do país e do mundo. Essa estratégia contribui para ampliação de conhecimentos, trazendo avanços para o campo da Estomaterapia e melhorando o atendimento à clientela.

Por conseguinte, participar dessa experiência inovadora tem sido gratificante e profícua, pois possibilita o acesso a outras formas de ensinar e aprender, contribui para nossa capacitação, uma vez que nos instrumentaliza no contato com tecnologias de ensino arrojadas.

\section{Referências}

1. Rodrigues RCV, Peres HHC. Panorama brasileiro do ensino de enfermagem a distância. Rev Esc Enferm USP. 2008 jun; 42(2): 298-304.

2. Faria MGA, David HMSL. Telessaúde Brasil Redes - núcleo Rio de Janeiro: a educação permanente no trabalho de enfermeiros da atenção básica. J Bras Tele. 2012. 1(1):23-24.

3. Telessaúde UERJ. Quem somos. Rio de Janeiro. Universidade do Estado do Rio de Janeiro, 2011. [acesso em 2013 ago 20]. Disponível em: http://www.telessaude.uerj. $\mathrm{br} /$ site/quem-somos.php.

4. Oliveira MAN. Educação a distância como estratégia para educação permanente em saúde: possibilidades e desafios. Rev Bras Enferm. 2007;60(5):585-9.

5. Cursos de Especialização em Estomaterapia no Brasil. [acesso em 2013 ago 25]. Disponível em: http://www.sobest.org.br/index.php?option=com_content\&amp;vie $\mathrm{w}=$ article\&amp;id=48\&amp;|temid $=48$ 